\title{
In-Body Power Distribution for Abdominal Monitoring and Implant Communications Systems
}

\author{
Mariella Särestöniemi ${ }^{1}$, Carlos Pomalaza-Raez ${ }^{2}$, Markus Berg ${ }^{1}$, Chaïmaâ Kissi ${ }^{3}$, Matti Hämäläinen ${ }^{1}$, Jari Iinatti ${ }^{1}$ \\ ${ }^{1}$ Center for Wireless Communications, University of Oulu, Finland, \\ ${ }^{2}$ Department of Electrical and Computer Engineering, Purdue University, Fort Wayne, Indiana, USA, \\ ${ }^{3}$ Electronics and Telecommunication Systems Research Group, National School of Applied Sciences (ENSA), Ibn Tofail \\ University, Kenitra, Morocco
}

\{firstname.familyname\}@ oulu.fi

\begin{abstract}
This paper presents a study on the power distribution within the tissues for abdominal monitoring and implant communications systems. This study is carried out using finite integration technique based simulations with an anatomical voxel model as well as with recently introduced directive on-body antennas designed for in-body communications. The investigation is conducted by evaluating $2 \mathrm{D}$ power flow on the cross-cut of the abdomen area to illustrate the propagation inside the different abdominal tissues. Additionally, power values in different parts of the abdomen area, such as in different parts of the small intestine (SI), colon, stomach etc., are calculated. The main purpose is to examine power distribution in the abdominal area with different antenna location options suitable for abdomen monitoring systems. Furthermore, channel characteristics between an endoscope capsule and an on-body antenna are evaluated in two different areas of the SI tract: close to the on-body antenna and further from the on-body antenna. Power distribution information is useful when designing the medical and health monitoring devices for the abdomen area, such as capsule endoscope, gastrointestinal activity monitoring systems, etc.
\end{abstract}

Index Terms -Directive antenna, capsule endoscopy, gastrointestinal monitoring system, in-body propagation and power loss

\section{INTRODUCTION}

Recently, there is increasing interest for developing new medical and health monitoring systems to relieve the problems and demands of healthcare due to aging population. [1]-[4]. Gastrointestinal (GI) diseases have growing trend in the developed countries and thus, the GI monitoring systems such as stomach, small intestine (SI) and colon monitoring systems, as well as capsule endoscopy, have been under an intensive study in recent years [5]-[6].

Capsule endoscopy, which provides reliable, painless, and comfortable way to examine GI track thoroughly, is already commonly used method in large hospitals. Human's GI system covers relatively large area, as presented in Figure 1 [7]. Thus, some of the capsules are targeted only to small intestine area or colon area separately [5]. However, with properly designed antennas and carefully selected antenna locations, monitoring of the GI track thoroughly is feasible.

In the capsule endoscopy, the embedded camera inside the capsule takes pictures while it travels along the GI tract and send the pictures to a monitoring device hanging on the waist belt of the user. The patient returns the monitoring device to the doctor on the next day for the image check. However, in many cases it would be useful that the doctor could remotely monitor the images in a real time, i.e. the device could send the monitoring data directly to the hospital. One option to realize such GI remote monitoring system is to combine Wireless Body Area Networks (WBAN) and 5G functionalities, as explained e.g. in [8]. WBAN application could collect the sensor data and the images sent by the implant. Then, the wearable device could send the collected data and images to the hospital though 5G.[8]

There are several benefits for applying UWB for the implant communications [8]. In our study case, the on-body antennas are designed for $3.75-4.25 \mathrm{GHz}$ which meets the requirements of WBAN standard IEEE802.15.6 [9]. Besides, the frequency band belongs to $5 \mathrm{G}$ frequency range in the USA and partly in Europe as well.

Smooth design of the wearable and implant communications system requires deep knowledge of the propagation and radio channel characteristics in the vicinity or inside the human body. Thus, the on-body and in-body channel characteristics have been under an intensive study recently [10]-[20]

The main target of this paper is to provide a study on the in-body power distributions within the tissues using different antenna location options suitable for abdomen monitoring systems. The investigation is conducted by evaluating 2D power flow on the cross-cuts of the abdomen area to illustrate the propagation inside the different abdominal tissues. Power values in different parts of the abdomen area, such as in different parts of the SI, colon, stomach etc., are calculated. Furthermore, radio channel characteristics between an endoscope capsule and on-body antenna are evaluated in two different parts of SI tract: in the areas with higher and lower powers.

This paper is organized as follows: Section II describes the study case providing information about the simulation model, antennas, and antenna locations options. Section III provides power evaluations and Section IV presents the results with capsule and on-body antenna. Finally, Conclusions are given in the Section V. 


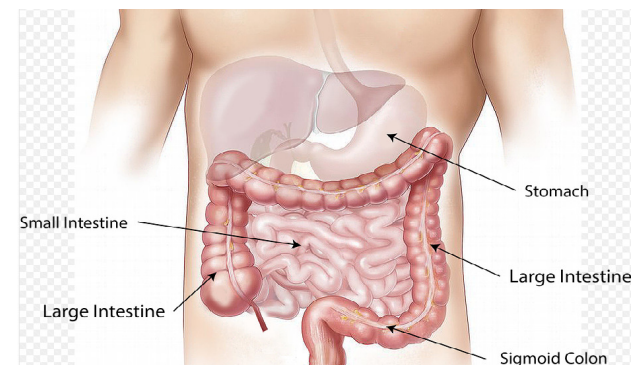

Figure 1. Gastrointestinal track of the human body [7].

\section{STUDY CASE}

\section{A. Simulation model}

Simulations were conducted using electromagnetic simulation software CST MicroWave Studio [21] which is based on finite integration technique (FIT). CST provides several voxel models, among which we selected an anatomical voxel model Laura, presented in Fig, 2a. Laura correspond to lean female body with resolution of $(1.87 \times 1.87 \times 1.25) \mathrm{mm}$. Cross-cut of the voxel models abdomen area on the navel line is shown in Fig 2b. Subcutaneos and visceral fat, muscles, SI, and colon (large intestine) are marked in the figure. CST material library has dielectric properties for different human body tissues at different frequencies. The dielectric properties for the tissues relevant in this study are presented in Table I.

In this study, we focus on the different parts of the GI tract, with three different cross-cut levels of the voxel model. Cross-cut lines and the corresponding cross-cut figures are presented in Fig 2. Figure $2 b$ is the cross-cut at the line A (for monitoring the upper part of the SI). Figs b-c are the cross-cuts at the lines B (for colon monitoring), and C (for monitoring the lower part of SI), respectively.

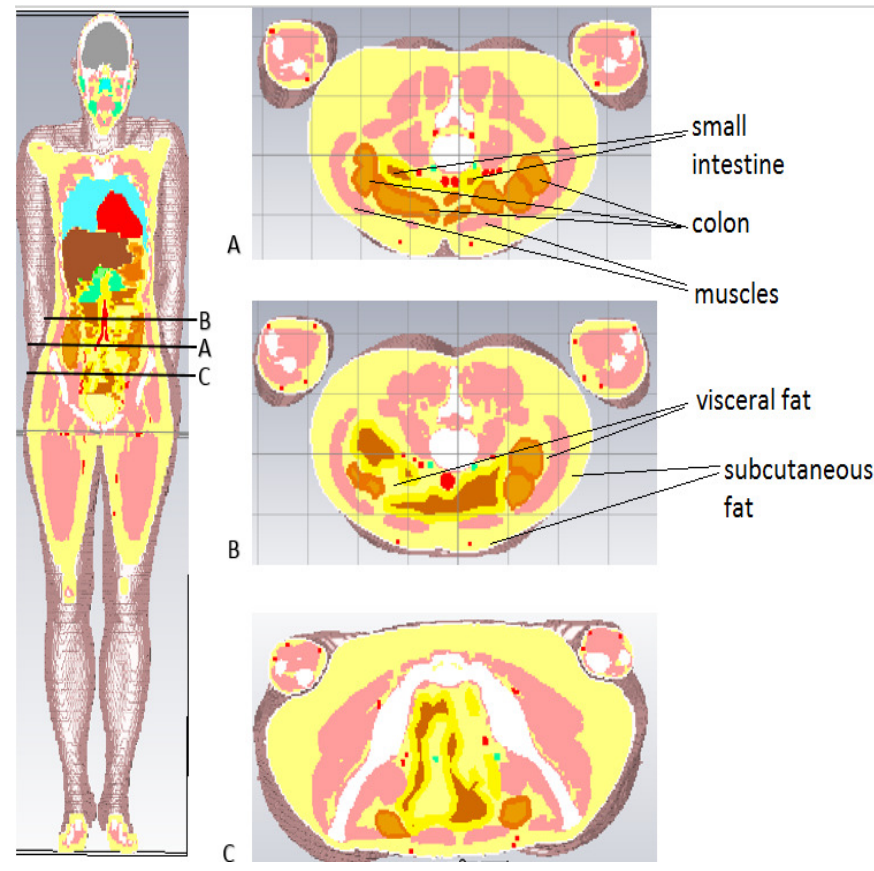

Fig. 2 a) Anatomical voxel model Laura, b) cross cut $\mathrm{A}$ of the abdomen area c) cross cut $\mathrm{B}$ of the abdomen area, and d) cross cut $\mathrm{C}$ of the abdomen area,
TABLE I

DIELECTRIC PROPERTIES OF THE TISSUES

\begin{tabular}{|l|l|l|}
\hline Tissue & $\begin{array}{l}\text { Permittivity } \\
(4 \mathrm{GHz})\end{array}$ & $\begin{array}{l}\text { Conductivity } \\
(\mathrm{S} / \mathrm{m}) \\
(4 \mathrm{GHz})\end{array}$ \\
\hline Skin & 40.85 & 2.701 \\
\hline $\begin{array}{l}\text { Subcutaneous } \\
\text { fat }\end{array}$ & 5.125 & 0.1829 \\
\hline Muscle & 50.82 & 3.015 \\
\hline Visceral fat & 5.125 & 0.1829 \\
\hline SI wall & 50.82 & 3.015 \\
\hline SI content & 51.63 & 4.622 \\
\hline Colon & 51.31 & 3.45 \\
\hline Abdomen & 59.6 & 3.85 \\
\hline
\end{tabular}

\section{B. Antennas and antenna locations}

In this study case, we use a) a cavity-backed low UWB band on-body antenna [22] and b) a ring on-body antenna [23], both designed for in-body communications. The antennas a and $\mathrm{b}$ are both directional (towards the body) with $7 \mathrm{~dB}$ and 8 $\mathrm{dB}$ gains, respectively The schemas of the antennas are illustrated in Figs 2a-b. Details of the antenna properties can be found in [22] and [23]. Three different antenna location options were considered, all of them suitable for abdominal monitoring for different purposes. The antenna location options are presented in the Figure 4 a-c.

In the first antenna location option, the antenna is placed on the navel. The main advantage of this antenna location option is that since the navel is a kind of hollow on the abdomen, there is less tissue to propagate through. The benefit of locating antenna on the central line of the abdomen is that since there is no muscles on the central line, the part of the signal can travel towards intestine area without passing by the muscle layer, which is one of the most challenging tissues for the propagation due to its dielectric properties [24]. Third benefit of this antenna location is that the navel provides additional air on the below of the antenna, which is known to be beneficial for most of the antennas. In the second antenna location option, presented in Fig. 4b. The antenna is shifted on the left side from the central line. The main advantage of this antenna location option is that it covers the intestine area wider, especially the colon area on the in Fig. 4c. In the third antenna location option, the antenna is on the central line of the abdomen but shifted downwards from the first antenna location option. This location provides better view on the lower part of small intestine area.
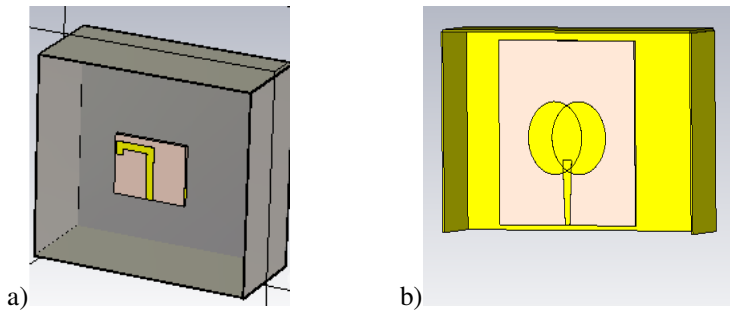

b)

Fig. 3 a) A cavity-backed low-band UWB on-body antenna and b) a ring onantenna designed for in-body communications 

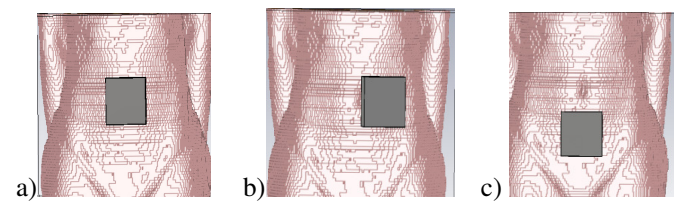

Fig. 4a-c Antenna locations options 1-3.

\section{Power evaluations}

The study is realized by evaluating propagation within the tissues by using 2D power flow patterns of the voxel model and determining the average power flow in different locations of the GI tract. The arrow-based power flow presentation is selected to illustrate the direction of the propagation in the tissues. Arrows also emphasize the diffraction that occurs when the signal enters from one tissue to another having different dielectric properties.

Furthermore, our aim is to evaluate and compare power flow values in certain locations of the GI tract with different antenna locations. The average power flow density $\mathbf{S}_{\mathrm{av}}$ is of interest here, it is related to the complex Poynting vector $\mathbf{S}$ as

$$
\mathbf{S}_{a v}=\frac{1}{2} \operatorname{Re}(\mathbf{S})=\frac{1}{2} \operatorname{Re}\left(\mathbf{E} \times \mathbf{H}^{*}\right)
$$

where $\mathbf{E}$ and $\mathbf{H}$ are the electric and the magnetic field intensity [25]. The CST simulator provides (x, y, z) three dimensional values for the electric and magnetic fields separately in the determined probe points, which are then used to calculate the average power flow.

\section{POWER EVALUATIONS}

This section presents the in-body distribution within the tissues on the abdomen area with different antenna location options. The size and color of the arrow describe the strength of the signal: the greener and larger the arrow is, the stronger is the signal.

\section{A. Vertical cross-cuts}

First we study the power flow on the abdomen area using the antenna "a" at the antenna location option 1 , as the cross-cut of the voxel model is performed via the central vertical line (along x-axis) in Fig. 5a. In this case, the plotted dynamic range is $60 \mathrm{~dB}$, i.e., the power is $0 \mathrm{~dB}$ on the skin surface and the smallest arrows corresponds to the signal strength about $60 \mathrm{~dB}$. It is noted that the propagation depth is sufficient to cover the upper part of the intestine area. Even the lower part of the stomach area is achieved within this $\mathrm{dB}$ dynamics: the average power in the abdomen is $-56 \mathrm{~dB}$.

However, the lower part of the small intestine area is not reached with the determined $\mathrm{dB}$ range. From the Fig. 5, it is easy to notice how the signal propagates easily through the fat layer, as explained in [26]. The losses are significantly lower than for instance in the SI, which can be predicted from Table I showing the significant lower permittivity for fat than for the small intestine. However, the muscle layer is one of the most challenging tissues for the propagation.

Fig. $5 \mathrm{~b}$ presents the cross-cut of the voxel model slightly shifted on the right along the $\mathrm{x}$-axis to get the muscles visible. One can clearly notice the impact of the muscle layer on the decreased power level at the colon area: the size of the arrows is smaller and the color is bluer. The average power loss between from the skin level to colon is approximately $-22 \mathrm{~dB}$ when the signal has to pass through the muscle layer width of 1 $\mathrm{cm}$ whereas the power loss is $-19 \mathrm{~dB}$ if the signal passes the central line without the muscles.
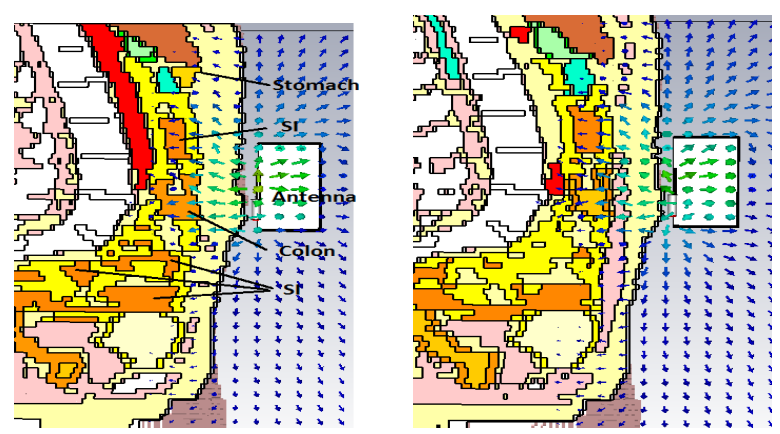

Figure 5a. Vertical cross-cut with the antenna location option 1 a) cross-cut at the central line b) cross-cut slightly shifted on the left to get the muscle impact visible

\section{B. Horizontal cross-cuts}

Next we evaluate power flow inside the tissues studying the horizontal cross-cuts A, B, and C, presented in Section II, for the voxel models with different antenna location options. First we consider the cross-cut at the level A.

\section{Cross-cut A}

Figure 6a presents the power flow with the antenna location option 1 at the cross-cut $\mathrm{A}$, which is the most suitable for observing power distribution on the colon area. One can note that within the determined $\mathrm{dB}$ range, the colon area is covered quite well. The arrows are relatively weak at the outermost colon parts in the sides. Instead, SI areas are relatively weakly covered within the determined dynamic range. The arrow presentation clearly shows, how the muscle tissue is challenging for the propagation whereas the fat is actually rather good propagation channel as presented in [26].

Fig. $6 \mathrm{~b}$ presents the power flow pattern with the antenna location option 2. Naturally in this case, the SI and colon areas are better covered in the left side whereas the right side power is clearly weaker.

Next, we determine power values on the selected locations: Colon back left (CB_L), Colon Back right (CB_R), Colon Front left CF_L, Colon Front right (CF_R), SI Back Right (SIB_R), SI Back Left (SIB_L). The values are presented in Table II for different GI tract locations with different antenna location options.

With the antenna location option 1, we can see differences between the averaged power flow values at left and right side of the abdomen although the antenna is located on the abdomen central line. The difference is due to the asymmetricity in the GI track as well as in the voxel model's abdominal muscle layers at this cross-cut level: at left side the muscle layer is lighter than on the right side. Since the propagation in the muscle layer is challenging due to the high losses, the power level is lower at the right side. 
In the case of the antenna location option 2, where the antenna is located on the left side of the abdomen, it is obvious that the power level is there higher on the left side than on the right side. However, when comparing the averaged power values on the left side of the abdomen with the antenna location option 1 and 2, one can note that the differences are less remarkable; just some $\mathrm{dB}$ both in colon and SI areas. This is assumed to be due to the benefits of locating antenna on the abdomen central line and especially above the navel, where there are less tissues to propagate through.

Next we evaluated the average power flow at the cross-cut level A with the antenna location option 3 in which the antenna is in the lower part of the abdomen. The idea is to present power flow at the GI track at the cross-cut line A as the antenna is clearly below the cross-cut line. As expected, power is clearly at lower level than in the antenna location options 1 and 2. However, in the front part of the colon, CF_L and CF_R, the average power level is relative high, roughly -57 $\mathrm{dB}$, whereas for the other locations it is lower than $-70 \mathrm{~dB}$. The reason for higher power is on the transversal colon is that the signal can propagate easily vertically through the fat layer as presented in Fig. 5 and thus the power loss is minor. Instead, with cross-cut A, the SI area is deeper inside the body behind the colon and thus the propagation through subcutaneous fat has no impact.

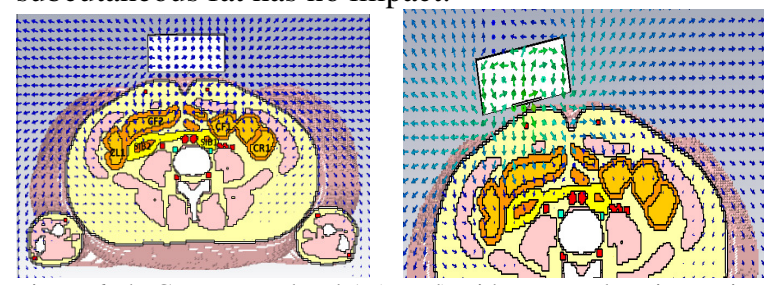

Figure 6a-b. Cross-cut at level A (navel) with antenna location options 1-2.

TABLE II

POWER AT DIFFERENT LOCATIONS IN THE ABDOMEN AREA AT CROSS-CUT A

\begin{tabular}{|l|l|l|l|}
\hline $\begin{array}{l}\text { Antenna loc. } \\
\text { GI location }\end{array}$ & 1 (navel) & 2 (side) & 3 below \\
\hline CL1 & $-55 \mathrm{~dB}$ & $-57 \mathrm{~dB}$ & $-71 \mathrm{~dB}$ \\
\hline CR1 & $-61 \mathrm{~dB}$ & $-61 \mathrm{~dB}$ & $-73 \mathrm{~dB}$ \\
\hline CF_L & $-22 \mathrm{~dB}$ & $-27 \mathrm{~dB}$ & $-57 \mathrm{~dB}$ \\
\hline CF_R & $-27 \mathrm{~dB}$ & $-64 \mathrm{~dB}$ & $-53 \mathrm{~dB}$ \\
\hline SIB_L & $-54 \mathrm{~dB}$ & $-42 \mathrm{~dB}$ & $-80 \mathrm{~dB}$ \\
\hline SIB_R & $-50 \mathrm{~dB}$ & $-70 \mathrm{~dB}$ & $-72 \mathrm{~dB}$ \\
\hline
\end{tabular}

\section{Cross-cut B: Upper part of SI}

Next we evaluate the average power flow with different antenna location options at the cross-cut B. The 2D power flow is presented in Fig. 7 for antenna location option 1. Due to lack of the space, we present the $2 \mathrm{D}$ power flow diagrams only for the antenna location option 1 in the following, but the numerical power results are provided in the tables for each antenna location option. This case covers: SI Front Left (SI_FL), SI Front Right (SI_FR), SI Middle (SI_M), SI Back (SI_B), and Colon Back (C_B). Moreover, CF_R and CF_L are considered as in the case of cross-cut $\mathrm{A}$. The results for different antenna location options are presented in Table III.
It should be noted that in this case SI_FL and SI_RL are not symmetrically located respect to the skin surface like C_FL and C_FR in the case of cross-cut A. SI_FR and SI_FL are located $7 \mathrm{~cm}$ and $2.5 \mathrm{~cm}$ below the skin surface, respectively. In the case of antenna location option 1, the difference between the average power flow at SI_FR and SI_FL is remarkable, even $23 \mathrm{~dB}$. With antenna location option 2 is even more significant: $64 \mathrm{~dB}$. These differences prove how the losses within the tissues can be remarkable. The power on the location SI_M is interesting: For the antenna location options 1 and 3 the power is $-31 \mathrm{~dB}$ and $-33 \mathrm{~dB}$, respectively. Instead, for the antenna location option 2 power is $-63 \mathrm{~dB}$. Again, the presence of the muscle layer effects destructively on the power level.

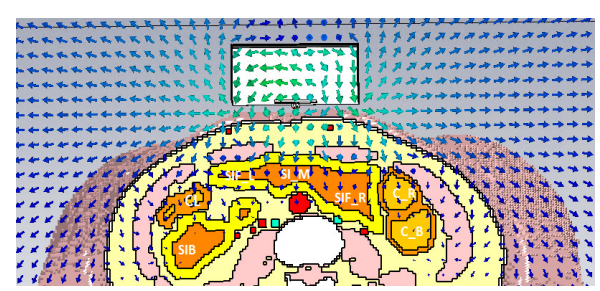

Figure 7. Cross-cut at level B (SI upper part) with antenna location options 1.

TABLE III

POWER AT DIFFERENT LOCATIONS IN THE ABDOMEN AREA AT CROSS-CUT B

\begin{tabular}{|l|l|l|l|}
\hline $\begin{array}{l}\text { Antenna location } \\
\text { GI location }\end{array}$ & 1 (navel) & 2 (side) & 3 (below navel) \\
\hline SI_FR & $-63 \mathrm{~dB}$ & $-71 \mathrm{~dB}$ & $-66 \mathrm{~dB}$ \\
\hline SI_FL & $-40 \mathrm{~dB}$ & $-27 \mathrm{~dB}$ & $-89 \mathrm{~dB}$ \\
\hline SI_M & $-31 \mathrm{~dB}$ & $-41 \mathrm{~dB}$ & $-33 \mathrm{~dB}$ \\
\hline SI_B & $-75 \mathrm{~dB}$ & $-38 \mathrm{~dB}$ & $-160 \mathrm{~dB}$ \\
\hline CF_L & $-38 \mathrm{~dB}$ & $-33 \mathrm{~dB}$ & $-67 \mathrm{~dB}$ \\
\hline CF_R & $-51 \mathrm{~dB}$ & $-60 \mathrm{~dB}$ & $-65 \mathrm{~dB}$ \\
\hline C_B & $-65 \mathrm{~dB}$ & $-71 \mathrm{~dB}$ & $-83 \mathrm{~dB}$ \\
\hline
\end{tabular}

\section{Cross-cut C: Lower part of SI}

Finally, the cross-cut $\mathrm{C}$ is evaluated with different antenna location options. In this case, there is roughly $5 \mathrm{~dB}$ difference between the $C_{-} R$ and $C_{-} L$ cases. This is due to the muscle layer: between the $C_{-} R$ there is no muscle layer in front of the location of SI_FR to go through and thus, the losses are minor. SI_F is relatively high level whereas SI_B is the most challenging, since it is so deep inside the tissues.

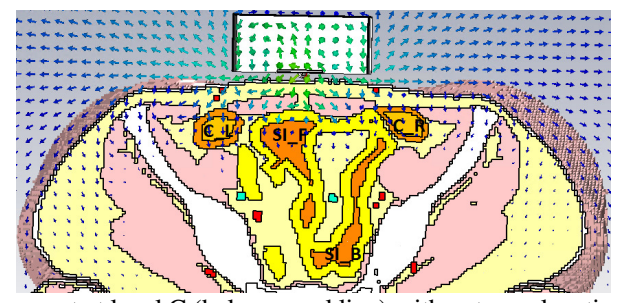

Fig. 8. Cross-cut at level C (below navel line) with antenna location option 1.

TABLE IV

POWER AT DIFFERENT LOCATIONS IN THE ABDOMEN AREA AT CROSS-CUT C

\begin{tabular}{|l|l|l|l|}
\hline $\begin{array}{l}\text { Antenna location/ } \\
\text { Power at GI parts }\end{array}$ & 1 (navel) & $2($ side) & $\begin{array}{l}3 \quad \text { (below } \\
\text { navel) }\end{array}$ \\
\hline C_R & $-47 \mathrm{~dB}$ & $-72 \mathrm{~dB}$ & $-35 \mathrm{~dB}$ \\
\hline C_L & $-44 \mathrm{~dB}$ & $-60 \mathrm{~dB}$ & $-40 \mathrm{~dB}$ \\
\hline SI_F & $-52 \mathrm{~dB}$ & $-61 \mathrm{~dB}$ & $-30 \mathrm{~dB}$ \\
\hline SI_B & $-116 \mathrm{~dB}$ & $-160 \mathrm{~dB}$ & $-97 \mathrm{~dB}$ \\
\hline
\end{tabular}




\section{Results with Ring antenna (antenna " $b$ ") at the antenna location option 1}

Next, we briefly evaluate the power distribution with the ring antenna at antenna location option 1 . The vertical and horizontal cross-cuts are presented in Fig 9a-d. The power values for different locations in the GI track are summarized in Table V. As it is noted, the power distribution is slightly different from those of the first antenna. This is due to the differences in the radiation patterns, as presented in [22] and [23]: the ring antenna has stronger horizontal beam towards the body whereas the beam of the first antenna is slightly tilted upwards. However, despite of these differences of the radiation patterns, the power distribution tendency is similar in both cases: power level is higher in the areas where the propagation through the muscle layer can be avoided and especially where the signal can propagate directly through the fat layer.
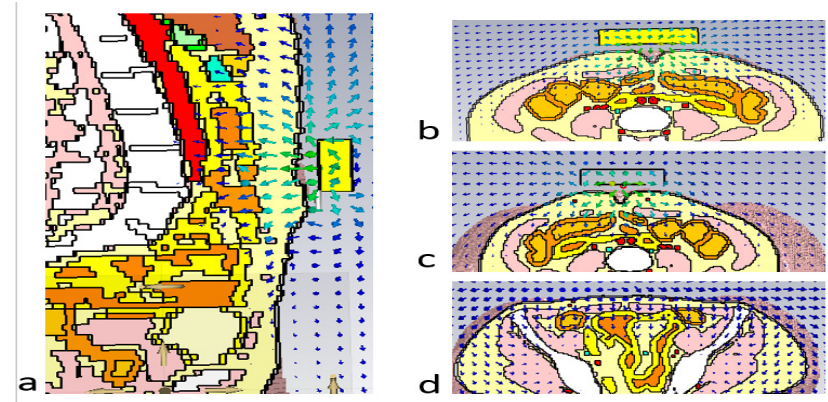

Figure 9. Power flows for cross-cuts: a) vertical, b) A, c) B, d) C with antenna location options 1.

TABLE V

POWER WITH RING ANTENNA AT CROSS-CUT A, B, AND C WITH ANTENNA LOCATION 1

\begin{tabular}{|l|l|l|l|l|l|}
\hline Crosscut & A & Crosscut & B & Crosscut & C \\
\hline CFR & $-55 \mathrm{~dB}$ & SIFR & $-61 \mathrm{~dB}$ & C_R & $-51 \mathrm{~dB}$ \\
\hline CFL & $-27 \mathrm{~dB}$ & SIFL & $-44 \mathrm{~dB}$ & C_L & $-49 \mathrm{~dB}$ \\
\hline CR1 & $-66 \mathrm{~dB}$ & SI_M & $-26 \mathrm{~dB}$ & SI_F & $-53 \mathrm{~dB}$ \\
\hline CL1 & $-68 \mathrm{~dB}$ & SI_B & $-38 \mathrm{~dB}$ & SI_B & $-116 \mathrm{~dB}$ \\
\hline SIBR & $-55 \mathrm{~dB}$ & CFL & $-33 \mathrm{~dB}$ & & \\
\hline SIBL & $-56 \mathrm{~dB}$ & CFR & $-60 \mathrm{~dB}$ & & \\
\hline & & C_B & $-71 \mathrm{~dB}$ & & \\
\hline
\end{tabular}

\section{EXAMPLE CASE: CHANNEL CHARACTERISTICS BETWEEN} THE CAPSULE ENDOSCOPE AND ON-BODY ANTENNA

In this section, we provide a practical example of the power difference in an implant communications system. We evaluate the radio channel characteristics between an endoscope capsule and on-body receiver antenna in two locations of SI: SI_FL and SI_FR. These locations have different power levels with the antenna location option 2 as described in Section III. Fig. 10 illustrates the modeled capsule in these locations.

The antenna inside the capsule is a simple omnidirectional dipole antenna designed for $4 \mathrm{GHz}$ frequency band. The antenna is located at the inside a plastic shelter with length $26 \mathrm{~mm}$ and width $11 \mathrm{~mm}$, which corresponds to the size of the commercially used capsules [27]. Figs $11 \mathrm{a}$ and b presents the path loss and impulse responses between the capsule antenna and the both on-body antennas "a" and "b".

One can note remarkable difference between the results obtained at SI_FL (blue curve) and SI_FR (red curve) locations. With the on-body antenna "a", the path loss is approximately $43 \mathrm{~dB}$ in SI_FL, whereas even $80 \mathrm{~dB}$ in SI_FR. With the on-body antenna "b", the path loss values for SI_FL and SI_FR are $-58 \mathrm{~dB}$ and $-87 \mathrm{~dB}$, so difference between these points is minor. In time domain, the difference between the main peaks of the impulse responses in approximately $30 \mathrm{~dB}$ with both antennas.

The difference between the path loss results obtained with the antennas "a" and "b" is due to the differences in the radiation patterns and especially in the main beams. As the capsule is closer, the stronger channel is obtained with the onbody antenna "a", whereas with the further location SI_FR the stronger channel is obtained with on-body antenna " $b$ ". In time domain, one can note time shift between the IRs obtained using the on-body antenna "a" and "b". The time is approximately $0.5 \mathrm{~ns}$. This time shift is assumed to be due to different structure of the antennas and the verification is left for the future work.

With the antenna location option 1, the results in SI_FR could be slightly improved based on the average power flow level at that location. However, the results might not be sufficient to receive data non-erroneously. Hence, the SI_FR results could be improved if another on-body antenna would be located at right side of the abdomen.
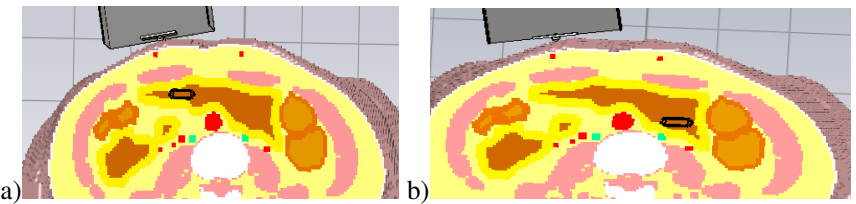

Figure 10. Simple capsule model located in a) SI_FL and b) SI_FR at the cross-cut B.

a)
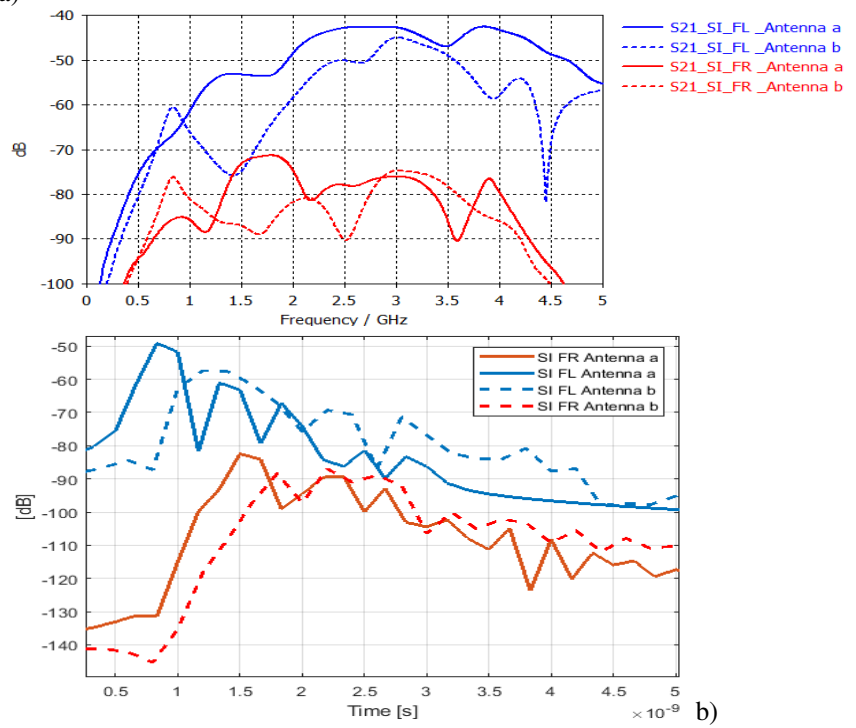

Figure 11. a) Path loss and b) impulse responses of the capsule-on-.body antenna link at SI FL and SI FR locations. 


\section{SUMMARY AND CONCLUSIONS}

This paper presented a study on the power distribution within the tissues for abdominal monitoring and implant communications systems. The investigation was conducted by evaluating $2 \mathrm{D}$ power flow on the cross-cuts of the abdomen area to illustrate the propagation inside the different abdominal tissues. Additionally, power values in different parts of the GI track, such as in different parts of the small intestine, colon, stomach etc., were calculated with different antenna location options. Average power inside the tissues depend not only on the distance from the skin but also type of tissues the signal has to travel through. Power loss is highest in the intestines and muscles, whereas lowest in the fat tissue. Evidently, radiation pattern and directivity of the antenna impact on the power as well. Furthermore, we evaluated as an example case the channel characteristics between a capsule antenna and an on-body antenna in two parts of the SI: the first SI part is very close to the body surface having and the on-body antenna whereas the second SI part is further from the skin surface and the on-body antenna. It is found that the difference between the channel strengths of these two parts is remarkable: around $40 \mathrm{~dB}$ difference.

Information about in-body power distribution within the tissues is useful when designing the medical and health monitoring systems for the abdomen area. Especially determining the locations for the on-body antennas is smoother. As a future work we plan to evaluate channel characteristics between the capsule antenna and the on-body antenna in different parts of the GI track with different antennas and on-body antenna locations.

\section{ACKNOWLEDGMENT}

This research has been financially supported by the project WBAN Communications in the Congested Environments and in part by Academy of Finland 6Genesis Flagship (grant 318927). Ilkka Virtanen, Timo Mäkinen, and Jari Sillanpää from University of Oulu deserve acknowledgement for their help to enable the exhaustive voxel simulations. Dr. Marko Sonkki is acknowledged for his participation on the on-body antenna design.

\section{REFERENCES}

[1] A. Teshome, B. Kibret, D. T. H. Lai, "A Review of Implant Communication Technology in WBAN, Progresses and Challenges," IEEE Reviews in Biomedical Engineering, 2018.

[2] E. Schires, P. Georgiou, T. S. Lande, "Vital Sign Monitoring Through Back Using an UWB Impulse Radar with Body Coupled Antennas," IEEE Transaction on Biomedical Circuits and Systems, 2018.

[3] Y. Wei, A. Zahid, H. Heidari, M. Imran, Q. H. Abbasi, A Compact NonInvasive Wearable Vital Signal Monitoring System," IEEE Asia Pasific Conference on Postgraduate Research in Microelectronics and Electronics, 2018.

[4] P. Leelatien, K. Ito, K. Saito, M. Sharma, A. Alomainy, "Channel Characteristics and Wireless Telemetry Performance of Transplanmted Organ Monitoring System Using Ultrawideband Communication," IEEE Journal of Electromagnetics, RF and Microwaves in Medicine and Biology, 2018.
[5] H. Mateen ; R. Basar ; A. U. Ahmed and M. Y. Ahmad, "Localization of Wireless Capsule Endoscope: A Systematic Review", IEEE Sensors Journal, Vol. 17, I. 5, pp. 1797 - 1206, 2017.

[6] R. Chavez-Santiago, J. Wang, I. Balasinham, "The Ultra Wideband Capsule Endoscope," Internatiomal Conf. on Ultra Wideband, 2013.

[7] https://pixabay.com/illustrations/abdomen-intestine-large-small$1698565 /$

[8] R. W. Jones, K. Katzis, "5G and Wireless Body Area Networks," IEEE Wireless Communications and Networking Conference Workshops (WCNCW), 2018.

[9] IEEE Standard for Local and metropolitan area networks Part 15.6: Wireless Body Area Networks, pp. IEEE Std 802.15.6-2012, 2012.

[10] A. F. Demir, Q. H. Abbasi, Z. E. Ankarali, A Alomainy, K.Qaraqe, E. Serpedin, H. Arsalan, "Anatomical Region-Specific In Vivo Wireless Communication Channel Characterization," IEEE Journal on Biomedical and Health Informatics, 2017.

[11] P. Turalchuk, I. Munina, V. Pleskachev, V. Kirillov, O. Vendik, I. Vendik, "In-Body and On-Body Wave Propagation: Modeling and Measurements," International Workshop on Antenna Technology: Small Antennas, Innovative Structures, and Applications(iWAT), 2017.

[12] Y. El-Saboni, G. A. Conway, S. L. Cotton, W. G. Scanlon, "Radiowave Propagation Characteristics in the Intra_Body Channel at $2.38 \mathrm{GHz}$, IEEE International Conference on Wearable and Implantable Body Sensor Networks (BSN), 2017.

[13] A. Alomainy, Y. Hao, Y. Yuan, Y. Liu, "Modelling and Characterization of Radio Propagation from Wireless Implants at Different Frequencies," European Conference on Wireless Technology 2009

[14] M. Särestöniemi, C. Pomalaza-Raez, T. Kumpuniemi, M. Hämäläinen, J. Iinatti, "Measurement Data Based Study on the Intra-Body Propagation in the Presence of the Sternotomy Wires and Aortic Valve Implant," Transaction on Antennas and Propagation, 2019.

[15] M. Särestöniemi, C. Pomalaza Raez., Z. Bi, T. Kumpuniemi, C. Kissi, M. Sonkki, M. Hämäläinen, J. Iinatti, "Comprehensive Study on the Impact of the Sternotomy Wires on the UWB WBAN Channel Characteristics," IEEE Access, 2019.

[16] M. Särestöniemi; C. Kissi;C. Pomalaza-Raez ; T. Kumpuniemi; M. Sonkki; S. Myllymäki ; M. Hämäläinen ; and J. Iinatti, "Measurement and simulation based study on the UWB channel characteristics on the abdomen area", ISMICT 2019.

[17] M. Särestöniemi; C. Kissi; C. Pomalaza-Raez ; M. Hämäläinen; and J. Iinatti, "Impact of the antenna-body distance on the UWB on-body channel characteristics", ISMICT 2019.

[18] M. Ilyas, O.N. Ucan, O. Bauat, X. Yang, Q. H. Abbasi, "Mathematical Modeling of UWB in vivo Radio Channel," IEEE Access 2018.

[19] Q. H. , Ankarali, Z. E., Alomainy, A., Qaraqe, K., Serpedin, E. and Arslan, H. "Anatomical region-specific in vivo wireless communication channel characterization," IEEE Journal of Biomedical and Health Informatics 2017.

[20] M. Särestöniemi, C. Kissi, C. Pomalaza Raez. M. Hämäläinen, J. Iinatti "Propagation and UWB channel characteristics on human abdomen area," EUCAP2019.

[21] CST Microwave Studio, [Online]. Available: http://www.cst.com

[22] C. Kissi; M. Särestöniemi; C. P-. Raez; M. Sonkki; and M. N. Srifi, "Low-UWB directive antenna for Wireless Capsule Endoscopy localization", BodyNets2018..

[23] C. Kissi ; M. Särestöniemi ; T. Kumpuniemi ; M. Sonkki ; S. Myllymäki ; M. N. Srifi and C. Pomalaza-Raez, " Low-UWB Receiving antenna for WCE Localization”, ISMICT 2019.

[24] https://www.itis.ethz.ch/virtual-population/tissue-properties/database

[25] S. J. Orfanidis, "Electromagnetic Waves and Antennas," 2002, revised 2016, online: http://www.ece.rutgers.edu/ orfanidi/ewa/.

[26] N. B. Asan, E. Hassan, JVSRM Shah, D. Noerland, T.J. Blokhuis, E. Wadbro, M. Berggren, T. Voig, R. Augustine, "Characterization of the Fat Channel for Intra-Body Communication at R-Band Frequencies," MDPI Sensors 2018, 2018.

[27] https://medical.olympusamerica.com/procedure/capsule-endoscopy 